\title{
Effect of different extraction solvents on antioxidant properties of water lily (Nymphaeaceae antares) flower petal and stamen
}

\author{
${ }^{1}$ Mohd Zin, Z., ${ }^{1}$ Sanuri, A.Z.M., ${ }^{1}$ Bashah, N., ${ }^{2}$ Ibrahim, K. ${ }^{3}$ Yahya, H. and ${ }^{1, *}$ Zainol M.K. \\ ${ }^{1}$ Faculty of Fisheries and Food Science, Universiti Malaysia Terengganu, Mengabang Telipot, 21030, \\ Kuala Nerus, Terengganu, Malaysia \\ ${ }^{2}$ Centre for Foundation and Continuing Education, Universiti Malaysia Terengganu, Mengabang Telipot, \\ 21030, Kuala Nerus, Terengganu \\ ${ }^{3}$ Faculty of Science and Technology, Universiti Sains Islam Malaysia, Bandar Baru Nilai, 71800 Nilai, \\ Negeri Sembilan, Malaysia
}

\begin{abstract}
Article history:
Received: 3 December 2020

Received in revised form: 4

January 2021

Accepted: 8 march 2021

Available Online: 27 June 2021
\end{abstract}

Keywords:

Antioxidant activities,

Nymphaea antares,

Solvents extraction

DOI:

https://doi.org/10.26656/fr.2017.5(3).653

\begin{abstract}
Water lily (Nymphaeaceae antares) contains a vast array of phenolic compounds with important natural antioxidative properties that could inhibit the adverse effects of the reactive oxygen species produced in living things. These substances are complex in composition which requires a suitable extraction medium to exploit the phenolic compounds. This study was designed to determine the antioxidative properties in petal and stamen of water lily extracted using different extraction solvents namely ethyl acetate and $60 \%$ methanol. Antioxidant properties of the samples were determined using 2,2-diphenyl -1-picrylhydrazyl (DPPH) radical scavenging activity, ferric thiocyanate (FTC) method, thiobarbituric acid (TBA) test, total phenolic content (TPC), total flavonoid content (TFC) and total tannin content (TTC) along with individual flavonoids content using High Performance Liquid Chromatography (HPLC). The yield of extract was found to be the highest in petals extracted with $60 \%$ methanol $(44.55 \pm 1.63 \%)$ while stamen extracted with ethyl acetate yielded the lowest $(24.50 \pm 1.09 \%)$. In the DPPH inhibition method, petal extracted with ethyl acetate obtained the highest scavenging activity $(89.15 \pm 3.62 \%)$. FTC analysis revealed that ethyl acetate extract of petal experienced the highest percentage inhibition $(76.70 \pm 6.48 \%$ ) while in TBA analysis ethyl acetate extract of stamen exhibited the highest percentage inhibition $(70.78 \pm 1.39 \%)$. Flavonoids such as quercetin, kaempferol, rutin, gallic acid, catechin, epigallocatechin, p-coumaric acid and myricetin were found to be present in ethyl acetate and $60 \%$ methanol extracts of water lilies stamen and petal. The information from this study indicates that water lily petals and stamens may be integrated as a good source of nutrients in the food industry, the pharmaceutical industry. If the advantages of water lily are not used and integrated into everyday life for health benefits, it will be a massive waste of natural resources.
\end{abstract}

\section{Introduction}

Poor diets are one of the major contributors to health issues such as chronic disease aetiologies such as heart disease and cancer in children and adults (Shukri et al., 2018). However, substantial evidence suggests that the use of natural plants plays a role in the maintenance and prevention of disease (Cory et al., 2018). However, determining what constitutes a balanced diet remains controversial, since it is difficult to unequivocally assign beneficial and harmful properties to the different components of the many foods we eat. Some of these protective effects may be due to flavonoids, which are widely distributed in plant-based foods at varying levels (Quero et al., 2020).

Flavonoids have recently attracted considerable concern due to their possible beneficial effects on human health (Chong et al., 2020). Antiviral, anti-allergic, antiplatelet, anti-inflammatory, antitumor and antioxidant activity has been identified (David et al., 2016). Flavonoids may help provide protection against these diseases by contributing, along with antioxidant vitamins and enzymes, to the total antioxidant defence system of the human body. Antioxidants are compounds that protect cells against the 
damaging effects of reactive oxygen species, such as singlet oxygen, superoxide, peroxyl radicals, hydroxyl radicals and peroxynitrite (da Silva et al., 2010). Recent studies have demonstrated that flavonoids found in fruits and vegetables may also act as antioxidants (Karak, 2019). This is the reason people nowadays are eagerly seeking safe natural antioxidants for consumption purposes. It is the responsibility of the food industry to develop new products containing flavonoids and perform research on various parts of plants to discover its type of flavonoids and the amount of antioxidant content that it holds (Panche et al., 2016).

Water lily is a tropical plant that requires a plentiful sunlight supply (Yu et al., 2018) that grows abundantly in Malaysia. Water lily is an aquatic plant frequently found along the edges of ponds, lakes, and streams (Crane and Friis, 2020). They have distinctive large rounded leaves or lily pads and flowers that can be white, yellow, or pink. In addition to proliferating in the wild, these plants are also grown in personal pleasure gardens and small water pools all over the world. Water lily is an aquatic herb of genus Nymphaea, from the family of Nymphaeaceae (Chen et al., 2017). The peduncle can push the leaves and flowers very high above the water. The roots of water lily can absorb poisonous substances like mercury, lead, phenol, and filter the microorganism in water, it plays an important role in decontaminating water, afforesting and landscaping (Zhu et al., 2012). Flowers and roots of water lily can both be made into tea and liquor, and the whole plant has been useful in the therapies of nephritis and is apparently a detoxicant and aphrodisiac along with astringent, diuretic properties (Yin et al., 2015).

It is hoped that the availability of antioxidant compounds in water lily would help to produce nutraceutical components in our food. "Nutraceutical" is defined as food or parts of food that provide medical or health benefits, including the prevention and treatment of disease (Lobo et al., 2010). It would be a huge waste of natural resources if the benefits of water lily are not exploited and incorporated into daily lives for health benefits. Each part of a plant holds different biological and chemical composition as well as verify flavonoids content and antioxidant activity. The major active nutraceutical ingredients in plants are flavonoids (Tapas et al., 2008).

In this study, the petal and stamen of water lily were used as the subject of study for antioxidative properties and flavonoids content. This study needs to be done to benefit future research, to justify that water lily could serve as a source of flavonoids which functions as a natural antioxidant and to assist in the development of nutraceutical products. This study is designed to determine the effect of different extraction solvents namely ethyl acetate and $60 \%$ methanol on the antioxidant activity in petal and stamen of water lily.

\section{Materials and methods}

\subsection{Raw material}

Water lily (Nymphaeaceae antares) stamen and petal (flower) were collected from a pond of a private residence situated in Kampung Lorong Bukit, Kuala Terengganu, Malaysia. The plant was identified by Tn $\mathrm{Hj}$. Mohamad Razali Salam, a plant botanist in Universiti Malaysia Terengganu. The water lily samples collected were three weeks old where the petiole had grown tall above the waters, fully bloomed flower at the end of it and the leaf of the plant had also grown to its maximum size. Water lily flower parts namely petal and stamen were selected for the different solvent extractions. The drying process was done immediately post-harvesting because water lily is known to have a short life span when it is out of its natural elements.

\subsection{Proximate analysis}

Proximate analysis of the raw materials was performed to assess the percentage of moisture, ash, crude protein, crude fat, and crude fibre based on the Association of Official Analytical Chemists' procedure (AOAC, 2007) standard procedure. Meanwhile, the carbohydrate content was calculated as Percentage of carbohydrate $=100-($ percentage $[$ protein + moisture + crude fat + ash + crude fibre]). All the analysis was carried out in triplicates.

\subsection{Sample preparation}

The flower petal and stamen from the water lily were separated from its other parts. The petal and stamen samples were washed and the excess water was drained on a piece of paper. The samples were cut into smaller sizes to ease the drying process. The samples were then kept in a freezer at $-4^{\circ} \mathrm{C}$ before being rapidly frozen by liquid nitrogen. Samples were then freeze-dried at $-42^{\circ} \mathrm{C}$ for 3-4 days and given pressure at $133 \times 10^{3} \mathrm{psi}$, with a vacuum of $105 \times 10^{-3}$ MBAR (LABCONCO Freeze Dry System, Model 195). After being fully dried, the samples were ground using a food processor and placed in an airtight container at $4^{\circ} \mathrm{C}$ (Hau et al., 2018).

\subsection{Sample extraction}

A total of $10 \mathrm{~g}$ of the dried water lily powdered sample was weighed into a conical flask, followed by the addition of $100 \mathrm{~mL}$ of $60 \%$ methanol and ethyl acetate. The mixture was placed in an incubator shaker at $25^{\circ} \mathrm{C}$ at 
a rate of 50 RPM. The mixture was then filtered (Whatman No. 4 filter paper) with the aid of a vacuum pump. The residue obtained was applied with the same amount of solvent and proceeded to be shaken for another $24 \mathrm{hrs}$. The extracted sample was then concentrated in a rotary evaporator for $3 \mathrm{hrs}$ and stored in an amber bottle at $-4^{\circ} \mathrm{C}$ (Zainol et al., 2018).

\subsection{2,2-diphenyl-1-picrylhydrazyl (DPPH) method}

The 2,2-diphenyl-1-picrylhydrazyl (DPPH) method was performed in accordance with the protocol defined by Looi et al. (2020) with some modifications. Four milligrams of petal and stamen extracts were dissolved in $1 \mathrm{~mL}$ methanol and assayed in triplicate. BHT and $\alpha$ tocopherol were used as a positive control for this analysis. A $3.0 \mathrm{~mL}$ of $0.1 \mathrm{Mm}$ methanol $\mathrm{DPPH}$ was added and vortexed well. The test tubes were allowed to stand at room temperature in the dark for $1 \mathrm{hr}$. The reduction of the DPPH free radical in the sample was measured by reading the absorbance at $517 \mathrm{~nm}$.

\subsection{Ferric thiocyanate (FTC) method}

The extracted water lily sample $(1 \mathrm{mg} / \mathrm{mL})$ was dissolved in $4 \mathrm{~mL}$ of absolute ethanol $(99.5 \%)$ and added with $4.1 \mathrm{~mL}$ of $2.52 \%$ linolenic acid in absolute ethanol. Eight millilitres of $0.05 \mathrm{M}$ phosphate buffer ( $\mathrm{pH} 7$ ) were mixed with $3.9 \mathrm{~mL}$ of distilled water and kept in a screw cap bottle and placed in a water bath shaker at $40^{\circ} \mathrm{C}$. An aliquot of $0.1 \mathrm{~mL}$ of samples was added to $9.7 \mathrm{~mL}$ of $75 \%$ ethanol and $0.1 \mathrm{~mL}$ of $30 \%$ ammonium thiocyanate finally by $0.1 \mathrm{~mL}$ of $0.02 \mathrm{M}$ ferrous chloride added in $3.5 \%$ hydrochloric acid into the reaction mixture. The absorbance of the resulting red-blood colour was measured after 3 mins at $500 \mathrm{~nm}$ every $24 \mathrm{hrs}$ until the day the absorbance of the control reached the maximum value ( $\mathrm{Ng}$ et al., 2020).

\subsection{Thiobarbituric acid (TBA) test}

Approximately $1 \mathrm{~mL}$ of sample solution obtained in the FTC method was added to $2 \mathrm{~mL}$ of $20 \%$ trichloroacetic acid and $2 \mathrm{~mL}$ of $0.67 \%$ 2-thiobarbituric acid. The mixture was placed in boiling water at $100^{\circ} \mathrm{C}$ for 10 mins. Next, the mixture was cooled and then centrifuged for $20 \mathrm{mins}$ at $3000 \mathrm{rpm}$. The absorbance of the supernatant was measured at $552 \mathrm{~nm}$ (Malik et al., 2017).

\subsection{Determination of total phenolic content (TPC)}

The total phenolic compounds were determined using the Folin-Ciocalteu reagent according to the colourimetric method described by Zainol et al. (2018). An aliquot $(1 \mathrm{~mL})$ of every sample was diluted into 50 $\mathrm{mL}$ of stock solution. An aliquot $(1 \mathrm{~mL})$ from the stock solution was added to $17.9 \mathrm{~mL}$ of distilled water in 0.5 $\mathrm{mL}$ of Folin-Ciocalteu reagent and left to stand for 1 min. Then, $1.5 \mathrm{~mL}$ of $20 \%$ sodium carbonate was added to the mixture. The sample prepared was then left at room temperature for $2 \mathrm{hrs}$ in the dark. The absorbance value was taken at $765 \mathrm{~nm}$, resulting in mg GAE per gram of sample extract (mg GAE/g) expressed as gallic acid equivalent.

\subsection{Determination of total flavonoid content (TFC)}

Fifty milligrams of the extracted samples were mixed with $1.5 \mathrm{~mL}$ methanol, $0.1 \mathrm{~mL} 10 \%$ aluminium chloride, $0.1 \mathrm{~mL} 1 \mathrm{M}$ potassium acetate and $2.8 \mathrm{~mL}$ distilled water. The mixture sample and reagents were then incubated for $30 \mathrm{mins}$ at room temperature $\left(25^{\circ} \mathrm{C}\right)$. The absorbance of the reaction mixture was then measured at $415 \mathrm{~nm}$. The result was expressed as $\mathrm{mg}$ of quercetin equivalent $(\mathrm{QE})$ per gram of sample extract (mg QE/g) as mg quercetin equivalent $(\mathrm{QE}) / \mathrm{g}$ of dried plant material (Chong et al., 2018).

\subsection{Determination of total tannin content (TTC)}

The total tannins content (TTC) were determined by the Folin-Ciocalteu method based on Kavitha Chandran and Indira (2016) with some modifications. Approximately $0.1 \mathrm{~mL}$ of the standard solution was added to, $7.5 \mathrm{~mL}$ of distilled water, $0.5 \mathrm{~mL}$ of FolinCiocalteu phenol reagent and $1 \mathrm{~mL}$ of $35 \% \mathrm{Na}_{2} \mathrm{CO}_{3}$ solution. The concoction was mixed well and let stand at room temperature $\left(25^{\circ} \mathrm{C}\right)$ for 30 mins. The absorbance of the test and standard solutions were measured against the blank at $725 \mathrm{~nm}$ using a UV/Visible spectrophotometer.

\subsection{Determination of flavonoids using HPLC}

All the extracted samples were refluxed in $6 \mathrm{M} \mathrm{HCl}$ at $90^{\circ} \mathrm{C}$ for $2 \mathrm{hrs}$ in a $60 \%(\mathrm{v} / \mathrm{v})$ aqueous methanol extracted prior to the HPLC analysis (Shukri et al., 2020). The quantification process was performed using an Analytical High-Performance Liquid Chromatography (HPLC) (Shimadzu, Japan) with a 4 solvent delivery system quaternary pump (LPG 3400 SD) including a diode array detector (DAD 3000) with $5 \mathrm{~cm}$ flow cell, a manual sample injection valve equipped with a $20 \mu \mathrm{L}$ loop and Chromeleon 6.8 system manager as the data processor. The samples and standards were eluted through A Zorbax $\mathrm{SB}_{-\mathrm{C}_{18}}$ reversed phase column $(150 \times 4.6 \mathrm{~mm})$ packed with $5 \mu \mathrm{m}$ diameter particles. Twenty microliters of sample were injected into the HPLC system for every analysis. The $1 \%(\mathrm{v} / \mathrm{v})$ of aqueous acetic acid solution and acetonitrile was used as the gradient mobile phase. The flow rate of the system was fixed at $0.7 \mathrm{~mL} / \mathrm{min}$, while the column oven was set at $28^{\circ} \mathrm{C}$. The composition of the mobile phase was back to the initial condition (solvent B: solvent A: 10: 90) in 
30 mins and allowed it to run for another 5 mins before the injection of the next sample. HPLC chromatograms were detected using a photodiode array UV detector at $270 \mathrm{~nm}$ (Khairil Anuar et al., 2020).

\subsection{Statistical analysis}

Data collected were statistically analyzed using statistical software, Minitab version 14 for windows (Minitab Inc., USA). One-way analysis of variance (ANOVA) with Tukey's Multiple Comparison Test was used to find the difference between means of samples using different extraction solvents for all responses with significant level $(\mathrm{p}<0.05)$. The results were expressed with substantial letters as mean \pm standard deviation (Chong et al., 2018).

\section{Results and discussion}

\subsection{Proximate analysis}

Table 1 indicates that fresh petals contain significantly $(\mathrm{p}<0.05)$ higher moisture content $(85.41 \pm 0.13 \%)$ than that of fresh stamen $(83.15 \pm 0.21 \%)$. The moisture content of a sample increases with bulk density, weight and volume. Since water lily is an aquatic plant, it is expected to enclose more water than plants that grow on land. Similarly, the dried petal $(11.01 \pm 0.11 \%)$ showed significantly $(\mathrm{p}<0.05)$ higher moisture content than that of dried stamen $(9.57 \pm 0.62 \%)$. A range of $8-11.5 \%$ of moisture content in the dried flowers will maintain quality for more than six months (Pandey, 2001). Odewo et al. (2014) quoted that the moisture content in leaves of water lily's stamen and petal (\% dry weight) was $1.88 \%$, which was lower compared to the current study. However, it should be noted that for dry matter, moisture content would depend on the degree of drying. It was clear that petals are larger in density, weight and volume than stamen. The higher value of ash content was obtained in the petal $(0.84 \pm 0.01 \%)$ compared to the stamen $(0.80 \pm 0.01 \%)$. Water lily stamen was found to exhibit a higher crude fat content $(0.77 \pm 0.01 \%)$ which might be due to the oily nature of the stamen (Tungmunnithum et al., 2020). Water lily stamen also exhibited a higher crude protein content $(3.85 \pm 0.01 \%)$ compared to the petals $(2.66 \pm 0.01 \%)$. The data also revealed that the crude content was found to be significantly $(\mathrm{p}<0.05)$ higher in petal $(3.35 \pm 0.02 \%)$ than that of stamen $(2.60 \pm 0.01 \%)$.
This study showed that water lily petals produce higher quantities of fibre than stamens. High fibre in the fruit sample may be attributed to the fibre content of water lily seeds and petals stated to be rich in insoluble dietary fibre (Ramaiya et al., 2018). Interestingly, this study shows that water lily's stamen and petal contain low in fat but at the same time high in carbohydrate. Carbohydrate was considered the highest composition in both the stamen and the petal. The amount of carbohydrate content was in accordance with Odewo et al. (2014), which recorded the highest components in the plant species.

\subsection{Effects of different solvents on the extraction yield of water lily petal and stamen}

The data shows that there was no significant $(p<0.05)$ difference in extraction yield between all parts of the flower and the solvents used to extract them. The yield of water lily petal extracted with $60 \%$ methanol was $44.55 \pm 1.63 \%$, whereas the yield of petal extracted with ethyl acetate was $25.90 \pm 4.14 \%$. The yield of water lily stamen extracted with $60 \%$ methanol was $32.28 \pm 3.06 \%$, while the yield of stamen extracted from ethyl acetate was $24.50 \pm 6.65 \%$. These results showed that the petal and stamen of water lily contain more polar compounds than non-polar compounds as both petal and stamen extracted using 60\% methanol (polar solvent) produced a higher yield than samples extracted in ethyl acetate.

However, due to the presence of numerous antioxidant compounds of various chemical characteristics and polarities which may or may not be soluble in a specific solvent, the extract yields and the resulting antioxidant activities of the plant materials are heavily dependent on the nature of the solvent extraction (Peschel et al., 2006). The differences in the extractive value between the petal and stamen of water lily may be due to the varying nature of the components present and the polarities of the solvent used for extraction (Gupta et al., 2013). Different extraction solvents have an effect on the percentage yield of samples. The recovery of antioxidant compounds from plant materials is generally achieved by different extraction techniques, taking into account their chemistry and unequal distribution in the plat matrix (Tao et al., 2010).

Table 1. Proximate composition and calorie content of $N$. antares (water lily) petal and stamen

\begin{tabular}{lccccccc}
\hline & \multicolumn{2}{c}{ Moisture content (\%) } & \multirow{2}{*}{ Fat (\%) } & Fibre (\%) & Protein (\%) & Ash (\%) & Carbohydrate (\%) \\
\cline { 2 - 6 } & Fresh & Dried & & & & & $7.17 \pm 0.01^{\mathrm{b}}$ \\
\hline Petal & $85.41 \pm 0.13^{\mathrm{a}}$ & $11.01 \pm 0.11^{\mathrm{a}}$ & $0.57 \pm 0.01^{\mathrm{a}}$ & $3.35 \pm 0.02^{\mathrm{a}}$ & $2.66 \pm 0.01^{\mathrm{b}}$ & $0.84 \pm 0.01^{\mathrm{a}}$ & 7 N $^{\mathrm{a}}$ \\
Stamen & $83.15 \pm 0.21^{\mathrm{b}}$ & $9.57 \pm 0.62^{\mathrm{b}}$ & $0.77 \pm 0.08^{\mathrm{a}}$ & $2.60 \pm 0.01^{\mathrm{b}}$ & $3.85 \pm 0.01^{\mathrm{a}}$ & $0.80 \pm 0.01^{\mathrm{a}}$ & $8.83 \pm 0.02^{\mathrm{a}}$ \\
\hline
\end{tabular}

Values are expressed as mean $\pm \mathrm{SD}, \mathrm{n}=3$. Values with different superscript within the same column are significantly different $(\mathrm{p}<0.05)$. 
3.3 Antioxidant properties in petal and stamen of Nymphaeaceae antares

\subsubsection{2,2-diphenyl-1-picrylhydrazyl (DPPH) radical scavenging activity}

Table 2 shows the 2,2-diphenyl-1-picrylhydrazyl $(\mathrm{DPPH})$ radical scavenging activity of water lily extracted using different solvents $(60 \%$ methanol for polar extraction and ethyl acetate for non-polar extraction). Water lily petal extracted in ethyl acetate showed the highest percentage inhibition $(91.53 \pm 0.74 \%)$ while petal extracted with $60 \%$ methanol obtained the lowest percentage inhibition $(88.43 \pm 2.86 \%)$. Kamarozaman et al. (2013), reported that the twigs of $V$. pauciflora extracted with ethyl acetate had the DPPH percentage inhibition of $65.46 \%$ whereas $58.05 \%$ when using methanol. Similarly, Aqil et al. (2006) stated that the activity of Trigonella foenum graecum (57\%) was at par when compared with the commercial antioxidant $\alpha$ tocopherol $(58 \%)$ and butylated hydroxytoluene, BHT $(49 \%)$. This indicated that the increased scavenging capacity of petal ethyl acetate may also be attributed to the hydrogen donation of components extracted from the sample. Complete extraction of active components, responsible for antioxidant activities, are strongly dependent on the nature of solvents and plant parts used. Flavonoids, tannins and other phenolic constituents present in food of plant origin are also potential antioxidants (Mandal, 2009).

\subsubsection{Ferric thiocyanate (FTC) method}

Figure 1 shows the antioxidative activity of the petal and stamen of water lily using different solvents such that $60 \%$ methanol and ethyl acetate measured using the FTC method for 6 days period. The lower value of absorbance indicates a higher value of the antioxidant activity. As can be seen, all samples exhibit high antioxidant activity, which is comparable to that of both $\alpha$-tocopherol and BHT (Mohd Zin et al., 2017). It was encouraging to note that there was no significant $(p<0.05)$ difference between all samples and standards.
The highest value of control was measured on the fifth day of incubation as it showed the control had achieved optimum level and gradually decreased on the sixth day. This is due to the oxidation of linoleic acid that generated linoleic acid hydroperoxides was decomposed into many secondary products. It showed a stoppage of oxidation of ferrous sulphate. The different parts of water lily with different extraction solvents showed different antioxidant activity in the FTC method which may be due to the reduction of hydroperoxides, inactivation of free radicals, chelation of metal ions or combination of them ( $\mathrm{Ng}$ et al., 2019).

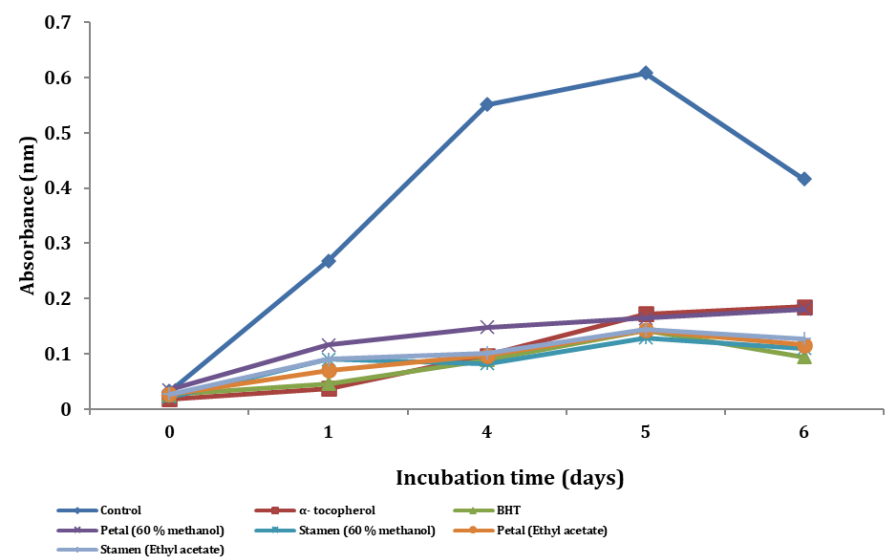

Figure 1. Antioxidant activity of petal and stamen of $N$. antares using 60\% methanol and ethyl acetate measured during the 6 days incubation period of FTC analysis

Table 2 also reveals that the antioxidant activity of water lily's petals extracted with ethyl acetate showed the highest antioxidant activity of all samples (76.70 $\pm 6.48 \%)$, surpassing the $\alpha$-tocopherol $(60.94 \pm 7.65 \%)$ and BHT $(75.04 \pm 3.34 \%)$. The findings also showed that the lowest antioxidant activity was achieved by the petals extracted with $60 \%$ methanol $(62.49 \pm 8.48 \%)$. This phenomenon may be due to the reduction of hydroperoxides, inactivation of free radicals, and chelation of metal ions or a combination of them (Phaniendra et al., 2014). Moreover, the phenolic compounds in the samples may donate hydrogen and can terminate the free reaction chain by changing it to stable

Table 2. Antioxidative activity (DPPH, FTC and TBA value), total phenolic content, total flavonoid contents and yield of sample $N$. antares stamen and petal extracted using $60 \%$ methanol and ethyl acetate

\begin{tabular}{|c|c|c|c|c|c|c|}
\hline & $\begin{array}{c}\text { Petal } \\
(60 \% \text { methanol }) \\
\end{array}$ & $\begin{array}{c}\text { Stamen } \\
(60 \% \text { methanol })\end{array}$ & $\begin{array}{c}\text { Petal } \\
\text { (Ethyl acetate) }\end{array}$ & $\begin{array}{c}\text { Stamen } \\
\text { (Ethyl acetate) }\end{array}$ & BHT & $\begin{array}{c}\alpha- \\
\text { Tocopherol } \\
\end{array}$ \\
\hline Extraction yield (\%) & $44.55 \pm 1.63^{\mathrm{a}}$ & $32.28 \pm 6.82^{\mathrm{a}}$ & $25.90 \pm 4.17^{\mathrm{a}}$ & $24.50 \pm 6.65^{\mathrm{a}}$ & - & - \\
\hline DPPH (\%) & $88.43 \pm 2.86^{\mathrm{a}}$ & $90.17 \pm 0.87^{\mathrm{a}}$ & $91.53 \pm 0.74^{\mathrm{a}}$ & $90.07 \pm 3.95^{\mathrm{a}}$ & $94.98 \pm 1.89^{\mathrm{a}}$ & $94.40 \pm 2.05^{\mathrm{a}}$ \\
\hline FTC $(\%)$ & $62.49 \pm 8.48^{\mathrm{a}}$ & $67.82 \pm 8.11^{\mathrm{a}}$ & $76.70 \pm 6.48^{\mathrm{a}}$ & $65.90 \pm 5.05^{\mathrm{a}}$ & $75.04 \pm 3.34^{\mathrm{a}}$ & $60.94 \pm 7.65^{\mathrm{a}}$ \\
\hline TBA $(\%)$ & $50.73 \pm 0.37^{\mathrm{c}}$ & $67.49 \pm 1.17^{\mathrm{a}}$ & $59.33 \pm 0.10^{\mathrm{b}}$ & $70.78 \pm 1.39^{\mathrm{a}}$ & $72.07 \pm 2.40^{\mathrm{a}}$ & $53.63 \pm 1.86^{\mathrm{bc}}$ \\
\hline TPC (mg GAE/g) & $82.21 \pm 7.42^{b}$ & $110.61 \pm 14.81^{\mathrm{a}}$ & $86.32 \pm 3.78^{b}$ & $118.83 \pm 7.73^{\mathrm{a}}$ & - & - \\
\hline TFC (mg QAE/g) & $69.21 \pm 6.79^{c}$ & $82.23 \pm 7.47^{b}$ & $77.32 \pm 6.84^{b}$ & $98.54 \pm 3.65^{\mathrm{a}}$ & - & - \\
\hline Total tannins content (mg TAE/g) & $38.34 \pm 3.63^{b}$ & $49.55 \pm 3.42^{\mathrm{a}}$ & $33.22 \pm 2.34^{\mathrm{c}}$ & $43.08 \pm 2.66^{\mathrm{b}}$ & - & - \\
\hline
\end{tabular}

Values are expressed as mean $\pm \mathrm{SD}, \mathrm{n}=3$. Values with different superscript within the same row are significantly different $(\mathrm{p}<0.05)$. 
compounds (Francenia Santos-Sánchez et al., 2019). FTC was used to measure the production of peroxide compounds at the initial stage of oxidation while TBA test was used to measure the secondary product of oxidation such as aldehyde and ketone (Huda-Faujan, 2009).

\subsubsection{Thiobarbituric acid (TBA) test}

Table 2 also demonstrates the antioxidant activity of petal and water lily stamen extracted using 60\% methanol and ethyl acetate, measured by the TBA method on the sixth day of incubation. The stamen sample extracted in ethyl acetate $(70.78 \pm 1.39 \%)$ had significantly the highest TBA inhibition value, while the lowest inhibition was petal extracted with $60 \%$ methanol $(50.73 \pm 0.37 \%)$. Petal extracted with $60 \%$ methanol showed a significant $(\mathrm{p}<0.05)$ difference with petal extracted with ethyl acetate. The differences in antioxidant activities observed between different parts of water lily and extraction solvents may be due to the different mechanisms involved in both determination methods, structures, of different phenolic compounds, the antioxidative mechanisms exhibited by the compound and the synergic effect of different compounds (Chong et al., 2018). The pattern of the thiobarbituric acid reactive material inhibitory behaviour of the samples is very close to that of the FTC test. This indicated that the reduction of thiobarbituric acid reactive substances in the samples may be due to the lower concentration of hydroperoxides in the respective samples. Besides that, secondary antioxidant compounds such as organic sulphur and organic nitrogen (Francenia Santos-Sánchez et al., 2019) that might be present in the samples may also contribute to the inhibition of hydroperoxides decomposition in these samples (Sasikumar and Menon, 2011). In comparison to the FTC method, the percentage inhibition of stamen ethyl acetate was $(65.90 \pm 5.05 \%)$ which was lower than the TBA method. This might suggest that the amount of peroxide in the initial stage of lipid peroxidation was less than the amount of peroxide in the secondary stage. Furthermore, the secondary product was much more stable for a period of time. All of the plant extracts exhibited strong antioxidant activity, comparable to standard commercial antioxidants of $\alpha$-tocopherol and BHT.

\subsubsection{Determination of total phenolic compound (TPC)}

The influence of tested solvents on crude extracts of water lily flower parts is presented in Table 2 . The data shows that the ethyl acetate stamen sample exhibited a higher total phenolic content (TPC) $(118.83 \pm 7.73 \mathrm{mg}$ $\mathrm{GAE} / \mathrm{g}$ ), followed by $60 \%$ methanol stamen $(110.61 \pm 14.81 \mathrm{mg} \mathrm{GAE} / \mathrm{g})$, ethyl acetate petal
$(86.32 \pm 3.78 \mathrm{mg} \mathrm{GAE} / \mathrm{g})$ and $60 \%$ methanol petal (82.21 $\pm 7.42 \mathrm{mg}$ GAE/g) respectively. It was also found that the TPC of the Stamen and petal extracts decreased with changes of solvent used from ethyl acetate to $60 \%$ methanol. This can be due to the content of more nonphenol compounds, such as carbohydrate and terpene, in extracts of methanol than in extracts of ethyl acetate. These phenolic compounds may have more phenol groups or higher molecular weights than phenols in the water extract (Metsämuuronen. and Sirén, 2019).

\subsubsection{Total flavonoid content (TFC)}

Table 2 also shows the vital results of the total flavonoid content (TFC) in which the ethyl acetate extract developed higher TFCs relative to methanol. Among the samples tested, the highest TFC was observed in ethyl acetate stamen $(98.54 \pm 3.65 \mathrm{mg}$ QAE/ g), followed by $60 \%$ methanol stamen $(82.23 \pm 7.47 \mathrm{mg}$ QAE/g), ethyl acetate petal $(77.32 \pm 6.84 \mathrm{mg}$ QAE/g) and $60 \%$ methanol petal $(69.21 \pm 6.79 \mathrm{mg} \mathrm{QAE} / \mathrm{g})$ with the lowest TFC value. It was observed that the effect of solvents on TFC is similar to that of TPC. This could indicate that flavonoids are the dominant phenolic group in water lily flower's petal and stamen extract. According to Banerjee et al. (2008) flavonoids are of paramount importance in plants where they act as shield protection from ultraviolet radiation.

\subsubsection{Total tannin content (TTC)}

Table 2 also shows the amount of tannin content (TTC) in water lily's stamen and petal extracted in $60 \%$ methanol and ethyl acetate. Higher TTC was observed in stamen extracted in $60 \%$ methanol $(43.08 \pm 2.66 \mathrm{mg} \mathrm{TAE} /$ g), followed by stamen extracted in ethyl acetate (49.55 $\pm 3.42 \mathrm{mg} \mathrm{TAE} / \mathrm{g})$, petal extracted in $60 \%$ methanol $(38.34 \pm 3.63 \mathrm{mg} \mathrm{TAE} / \mathrm{g})$, and finally, petal extracted in ethyl acetate $(38.34 \pm 3.63 \mathrm{mg} \mathrm{TAE} / \mathrm{g})$. The findings clearly showed that the stamen was more tannin -filled relative to the petal. This data also suggested that water lily petal and stamen contain more polar tannin than non-polar soluble tannin. It also reveals that the tannin in the water lily flower was considerably polar due to its solubility in the methanolic medium. Although tannins are water-soluble compounds, their solubility depends primarily on their hydrophobic and hydrogen bonding interactions (Cirkovic Velickovic and StanicVucinic, 2017). The presence of tannin could affect the structure and quality of phenolic compounds, which could further stimulate a positive increase in antioxidant activity (Minatel et al., 2017).

\subsection{Determination of flavonoids content}

Figure 2 shows the HPLC chromatogram, which verifies the existence of designated flavonoids in this 
analysis, identified by their retention times, confirming the presence of individual flavonoids in water lily petal and the stamen sample undergoing different solvent extraction. All samples showed the presence of catechin, epigallocatechin gallate, quercetin, gallic acid, myricetin, kaempferol, rutin and p-coumaric acid (Figure 2). Sepahpour et al. (2018) previously reported that the $80 \%$ ethanol extraction yielded $0.9,5.4,2.4$ and $1.4 \mathrm{mg} / \mathrm{g}$ freeze- crude extract of rutin, quercetin-3-glucoside myricetin and quercetin. It is interesting to note that water lily stamen dominated the concentration of individual flavonoids. Do et al. (2014) reported that aqueous solvent was better than non-aqueous solvent for extraction of the flavonoids from Limnophila aromatica, indicating that methanol was more effective than nonaqueous solvent.

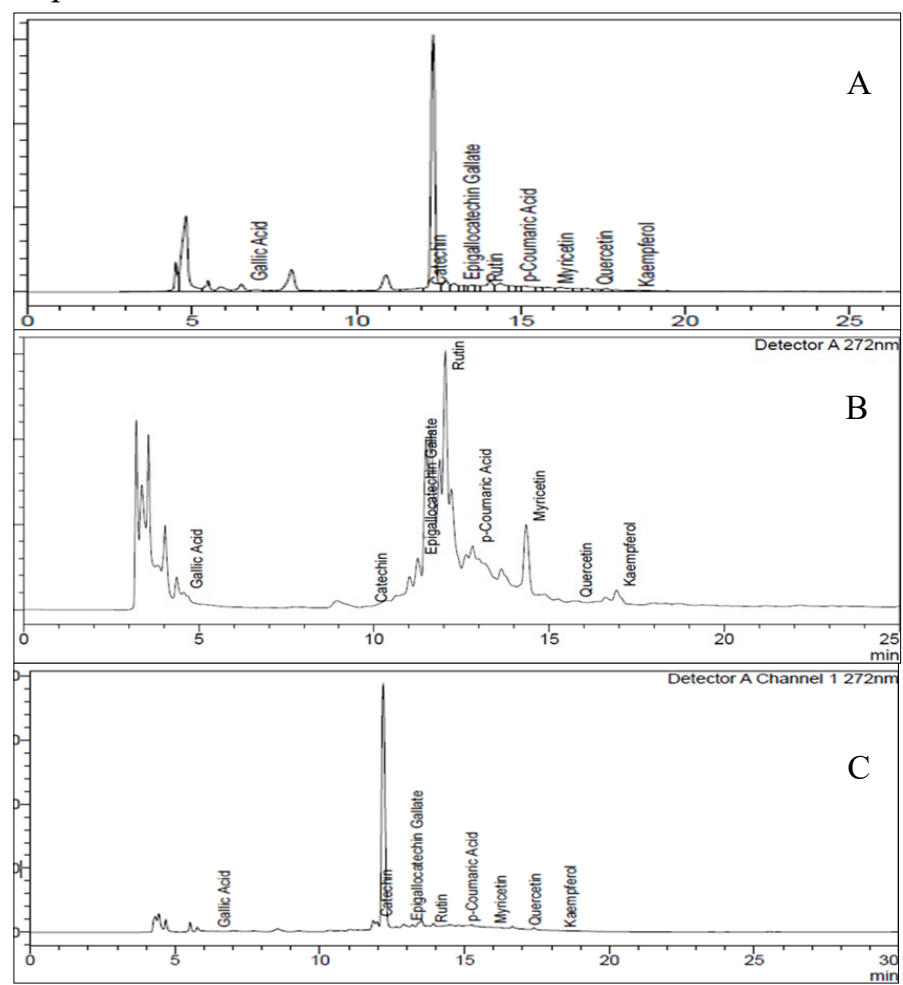

Figure 2. HPLC chromatograms of water lilies ( $N$. antares) stamen and petal extracted using 60\% methanol and ethyl acetate, A: $N$. antares petal in $60 \%$ methanol, B: $N$. antares stamen in $60 \%$ methanol, C: $N$. antares petal in ethyl acetate, D: $N$. antares stamen in ethyl acetate
Table 3 shows the findings of the HPLC analysis of flavonoid content in two parts of water lily (stamen and petal) extracted in $60 \%$ methanol and ethyl acetate. The findings also revealed that water lily extracted using $60 \%$ of methanol had a higher concentration of total individual flavonoids, whereas samples extracted in ethyl acetate showed a lower total of individual flavonoids. According to the findings, different solvents had major effects on the recovery of flavonoids. Catechin was found to be high in water lily stamen and petal extracted in $60 \%$ methanol. Moreover, the order of individual flavonoids found in the present study was catechin $>$ rutin $>$ gallic acid $>$ epigallocatechin gallate $>p$ coumaric acid $>$ myricetin $>$ quercetin $>$ kaempferol. The data clearly illustrated that catechin was the most abundant flavonoid for the entire sample where it ranged between $211.58 \pm 10.07 \mu \mathrm{g} / 100 \mathrm{~mL}$ to $8765.14 \pm 45.01$ $\mu \mathrm{g} / 100 \mathrm{~mL}$. Similar results were reported by $\mathrm{Ng}$ et al. (2019), who quoted that catechin was the most abundant flavonoid in black tea infused in $60^{\circ} \mathrm{C}$ water. In contrast, rutin was found to be the highest $(\rho>0.05)$ individual flavonoid in water lily stamen and petal extracted in ethyl acetate. Rødtjer et al. (2006) reported that a high content of phenolic compounds and flavonoids content in their studies were greatly dependent on the solvent polarity used as the extraction medium. Moreover, the order of individual flavonoids found in the present study wasrutin $>$ coumaric $>$ myricetin $>$ gallic acid $>$ epigallocatechin gallate $>$ quercetin $>$ kaempferol $>$ catechin. In contrast, Assefa et al. (2016) reported that quercetin is the major flavanol found in vegetables such as broccoli, kale, French beans, celery, onions and cranberries. In addition, rutin was found to be the least abundant flavonoid in all the samples tested. These variations in results obtained from the different extraction procedures between flavonoids could be explained by the different polar and non-polar properties of each type of flavonoids (Mohd Zainol et al., 2009).

Table 3. The concentration of individual flavonoids detected in $N$. antares (water lily) stamen and petal extracted using $60 \%$ methanol and ethyl acetate

\begin{tabular}{ccccc}
\hline & \multicolumn{3}{c}{ Concentration of flavonoids affected by the different solvent used $(\mu \mathrm{g} / 100 \mathrm{~mL})$} \\
\cline { 2 - 5 } & Petal Ethyl acetate & Petal 60 methanol & Stamen Ethyl acetate & Stamen $60 \mathrm{methanol}$ \\
\hline Catechin & $211.58 \pm 10.07^{\mathrm{Cg}}$ & $6458.28 \pm 270.69^{\mathrm{Ba}}$ & $345.21 \pm 26.75^{\mathrm{Cf}}$ & $8765.14 \pm 45.01^{\mathrm{Aa}}$ \\
Epigallocatechin Gallate & $813.37 \pm 57.88^{\mathrm{Ce}}$ & $1518.55 \pm 100.63^{\mathrm{ABc}}$ & $1023.88 \pm 147.52^{\mathrm{Bde}}$ & $2124.88 \pm 77.01^{\mathrm{Ac}}$ \\
Gallic acid & $1143.27 \pm 29.67^{\mathrm{Cd}}$ & $1548.37 \pm 97.89^{\mathrm{Bc}}$ & $1297.70 \pm 74.62^{\mathrm{Cd}}$ & $1978.69 \pm 69.06^{\mathrm{Ac}}$ \\
Kaempferol & $501.93 \pm 77.89^{\mathrm{CDf}}$ & $693.15 \pm 36.86^{\mathrm{Bd}}$ & $828.63 \pm 55.92^{\mathrm{Ade}}$ & $443.93 \pm 56.61^{\mathrm{De}}$ \\
Myricetin & $1979.17 \pm 90.05^{\mathrm{Ac}}$ & $812.83 \pm 55.39^{\mathrm{Cd}}$ & $2269.84 \pm 123.94^{\mathrm{Ac}}$ & $1113.26 \pm 16.23^{\mathrm{Bd}}$ \\
P-Coumaric Acid & $3001.06 \pm 200.65^{\mathrm{Ab}}$ & $1443.82 \pm 59.28^{\mathrm{Bc}}$ & $3241.16 \pm 473.61^{\mathrm{Ab}}$ & $1211.37 \pm 97.07^{\mathrm{Bd}}$ \\
Quercetin & $519.43 \pm 37.44^{\mathrm{Bf}}$ & $674.17 \pm 14.67^{\mathrm{Bd}}$ & $1000.56 \pm 69.48^{\mathrm{Ad}}$ & $545.24 \pm 49.49^{\mathrm{Be}}$ \\
Rutin & $6111.84 \pm 100.56^{\mathrm{Aa}}$ & $4002.12 \pm 89.26^{\mathrm{Bb}}$ & $6320.25 \pm 349.25^{\mathrm{Aa}}$ & $4992.30 \pm 27.89^{\mathrm{Bb}}$ \\
\hline
\end{tabular}

Values are expressed as mean $\pm \mathrm{SD}, \mathrm{n}=3$. Values with different lowercase superscript within the same column are significantly different $(p<0.05)$ while values with different uppercase superscript within the same row are significantly different $(p<0.05)$. 


\section{Conclusion}

The present study has shown that the yield and efficiency of phenolic compound and flavonoid extraction depends on the form and type of solvent that is extracted. The yield of water lily extract was found to be higher in petals extracted with 60\% methanol $(44.55 \pm 1.63 \%)$ while the stamen extracted with ethyl acetate was the lowest $(24.50 \pm 1.09 \%)$. Flavonoids such as quercetin, kaempferol, rutin, gallic acid, catechin, epigallocatechin, p-coumaric acid and myricetin were found to be present in all water lilies stamen and petal ethyl acetate and $60 \%$ methanol extracts. Catechin and rutin were found to be dominant in $60 \%$ methanol and ethyl acetate, respectively. Compared to ethyl acetate, the total phenolics, flavonoids and tannin extraction of $60 \%$ methanol from stamen was more efficient. The analysis also reveals that Petal of ethyl acetate was effectively free radical scavengers, likely functioning as the main antioxidant.

\section{Conflict of interest}

The authors declare no conflict of interest.

\section{Acknowledgement}

This research was funded by UMT short-term grant (Research Incentive Grants /GGP(UMT / RMIC/22/2/25/6(73). The authors would like to thank the Faculty of Fisheries and Food Science (FPSM) as well as UMT Research and Field Service Centre for the facilities to conduct this study.

\section{References}

AOAC. (2007). Official Methods of Analysis of AOAC International. AOAC Official Method 990.26. 17th ed. Gaithersburg, MD, USA: AOAC International

Aqil, F., Ahmad, I. and Mahmood, Z. (2006). Antioxidant and free radical scavenging properties of twelve traditionally used Indian medicinal plants. Turkish Journal of Biology, 30, 177-183.

Assefa, A.D., Ko, E.Y., Moon, S.H. and Keum, Y.-S. (2016). Antioxidant and antiplatelet activities of flavonoid-rich fractions of three citrus fruits from Korea. 3 Biotech, 6(1), 109. https://doi.org/10.1007/ s13205-016-0424-8

Banerjee, D., Chakrabarti, S., Hazra, A.K., Banerjee, S., Ray, J. and Mukherjee, B. (2008). Antioxidant activity and total phenolics of some mangroves in Sundarbans. African Journal of Biotechnology, 7(6), 805-810.

Chen, F., Liu, X., Yu, C., Chen, Y., Tang, H. and Zhang, L. (2017). Water lily as emerging models for
Darwin's abominable mystery. Horticulture Research, 4, 17051. https://doi.org/10.1038/ hortres.2017.51

Chong, K.H., Majid, N.I., Mohd Yusof, H., Zainol, M.K., Mohamad, H. and Mohd Zin, Z. (2020). Catechin profile and hypolipidemic activity of Morinda citrifolia leaf water extract. Heliyon, 6(6), e04337.

https://doi.org/10.1016/ j.heliyon.2020.e04337

Cirkovic Velickovic, T.D. and Stanic-Vucinic, D.J. (2017). The role of dietary phenolic compounds in protein digestion and processing technologies to improve their antinutritive properties. Comprehensive Reviews in Food Science and Food Safety, 17(1), 82-103. https://doi.org/10.1111/15414337.12320 .

Cory, H., Passarelli, S., Szeto, J., Tamez, M. and Mattei, J. (2018). The role of polyphenols in human health and food systems: A mini-review. Frontiers in Nutrition, 5, $87 . \quad$ https://doi.org/10.3389/ fnut.2018.00087

Crane, P.R. and Friis, E.M. (2020). Water lily, loss of woodiness, and model systems. Proceedings of the National Academy of Sciences, 117(18), 9674-9676. https://doi.org/10.1073/pnas.2005075117

da Silva, M.F., Marques, A. and Chaveiro, A. (2010). Reactive Oxygen Species: A Double-Edged Sword in Reproduction. The Open Veterinary Science Journal, 4(1), 127-133. https:// doi.org/10.2174/1874318801004010127].

David, A.V.A., Arulmoli, R. and Parasuraman, S. (2016). Overviews of Biological Importance of Quercetin: A Bioactive Flavonoid. Pharmacognosy Reviews, 10(20), 84-89. https://doi.org/10.4103/0973 -7847.194044 .

Do, Q.D., Angkawijaya, A.E., Tran-Nguyen, P.L., Huynh, L.H., Soetaredjo, F.E., Ismadji, S. and Ju, Y. -H. (2014). Effect of extraction solvent on total phenol content, total flavonoid content, and antioxidant activity of Limnophila aromatica. Journal of Food and Drug Analysis, 22(3), 296-302. https://doi.org/10.1016/j.jfda.2013.11.001

Francenia Santos-Sánchez, N., Salas-Coronado, R., Villanueva-Cañongo, C. and Hernández-Carlos, B. (2019). Antioxidant compounds and their antioxidant mechanism. Antioxidants. https://doi.org/10.5772/ intechopen. 85270 .

Gupta, S., Sarma, S., Mao, A.A. and Seal, T. (2013). Antioxidant activity of different parts of Lysimachia laxa and Gymnocladus assamicus, a comparison using three different solvent extraction systems. Journal of Chemical and Pharmaceutical 
Research, 5(4), 33-40.

Hau, E.H., Amiza, M.A., Mohd Zin, Z. and Zainol, M.K. (2018). The properties, compositions and qualities of Yellowstripe scad (Selaroides leptolepis) and its liquid protein hydrolysate based on different enzyme concentrations, hydrolysis time and choice of buffer. International Food Research Journal, 25(3), 11741180.

Huda-Faujan, N., Noriham, A., Norrakiah, A.S. and Babji, A.S. (2009). Antioxidant activity of plants methanolic extracts containing phenolic compounds. African Journal of Biotechnology, 8(3), 484-489.

Kamarozaman, A.S., Latip, J. and Zain, W.Z.W.M. (2013). Antioxidant properties of Vatica pauciflora and Vatica lowii crude extracts. Journal of Life Sciences and Technologies, 1(4), 205-209. https:// doi.org/ 10.12720/jolst.1.4.205-209.

Karak, P. (2019). Biological activities of flavonoids: An overview. International Journal of Pharmaceutical Sciences and Research, 10(4), 1567-1574. https:// doi.org/10.13040/IJPSR.0975-8232.10(4).1567-74

Kavitha Chandran, C.I. and Indira, G. (2016). Quantitative estimation of total phenolic, flavonoids, tannin and chlorophyll content of leaves of Strobilanthes kunthiana (Neelakurinji). Journal of Medicinal Plants Studies, 4(4), 282-286.

Khairil Anuar, M., Mohd Zin, Z., Juhari, N.H., Hasmadi, M., Smedley, K.L. and Zainol, M.K. (2020). Influence of pectinase-assisted extraction time on the antioxidant capacity of Spent Coffee Ground (SCG). Food Research, 4(6), 2054 - 2061. https:// doi.org/10.26656/fr.2017.4(6).270

Lobo, V., Patil, A., Phatak, A. and Chandra, N. (2010). Free radicals, antioxidants and functional foods: Impact on human health. Pharmacognosy Reviews, 4 (8), 118-126. https://doi.org/10.4103/09737847.70902

Looi, S.K., Zainol, M.K., Mohd Zin, Z., Hamzah, Y. and MohdMaidin, N. (2020). Antioxidant and antibacterial activities in the fruit peel, flesh and seed of Ceri Terengganu (Lepisanthes alata Leenh.). Food Research, 4(5), 1600-1610. https:// doi.org/10.26656/fr.2017.4(5).172

Malik, N.H., Mohd Zin, Z., Abd Razak, S.B., Ibrahim, K. and Zainol, M.K. (2017). Antioxidant activity and flavonoids contents in leaves of selected Mangrove species in Setiu Wetland. Journal of Sustainability Science and Management, 2017(3), 24-34.

Mandal, S., Yadav, S., Yadav, S. and Nema R.K. (2009). Antioxidants: a review. Journal of Chemical and Pharmaceutical Research, 1(1), 102-104.

Metsämuuronen, S. and Sirén, H. (2019). Bioactive phenolic compounds, metabolism and properties: a review on valuable chemical compounds in Scots pine and Norway spruce. Phytochemistry Reviews, 18, 623-664. https://doi.org/10.1007/s11101-01909630-2

Minatel, I.O., Borges, C.V., Ferreira, M.I., Gomez, H.A.G., Chen, C.-Y.O. and Lima, G.P.P. (2017). Phenolic compounds: Functional properties, impact of processing and bioavailability. In Soto-Hernande, M. (Ed.) Phenolic Compounds - Biological Activity. InTech Open E-Book. https://doi.org/10.5772/66368.

Mohd Zin, Z., Phang, Y.M., Zuraidah, N., Chong, K.H. and Zainol, M.K. (2017). Effect of pre-treatment on physical properties, ascorbic acid and $\beta$-carotene content of frozen Sweet Corn Kernels Hibrimas (Zea mays var Saccharata Bailey) variety. Malaysian Applied Biology, 46(3), 23-31.

Ng, K.S., Mohd Zin, Z., MohdMaidin, N. and Zainol, M.K. (2020). The ramification of fermentation time on antioxidant properties of Napier grass herbal tea by black tea processing method. Food Research, 4 (2), 349-357. https://doi.org/10.26656/fr.2017.4 (2). 265

Ng, K.S., Mohd Zin, Z., MohdMaidin, N., Abdullah, M.A.A. and Zainol, M.K. (2019). Effect of drying temperatures on antioxidant properties of Napier grass (Pennisetum purpureum). Asian Journal Agricultural and Biology, 7(1), 39-48.

Odewo, S.A., Agbeja, A.O., Olaifa, K.A., Ojo, A.P. and Ogundana, S.A. (2014). Proximate and spectroscopic analysis of Passiflora foetida L. International Journal of Scientific and Technology Research, 3(9), 353-356. ISSN 2277-8616.

Panche, A.N., Diwan, A.D. and Chandra, S. R. (2016). Flavonoids: An overview. Journal of Nutritional Science, 5, e47. https://doi.org/10.1017/jns.2016.41

Pandey, P.H. (2001). Principles and practices of postharvest technology, p. 331-335. New Delhi, India: Kalyani Publishers.

Peschel, W., Sanchez-Rabaneda, F., Dn, W., Plescher, A., Gartzia, I., Jimenez, D., Lamuela-Raventos, R., Buxaderas, S. and Condina, C. (2006). An industrial approach in the search of natural antioxidants from vegetable and fruit wastes. Food Chemistry, 97(1), 137-150.

j.foodchem.2005.03.033

Phaniendra, A., Jestadi, D.B. and Periyasamy, L. (2014). Free radicals: Properties, sources, targets, and their implication in various diseases. Indian Journal of Clinical Biochemistry, 30(1), 11-26. https:// doi.org/10.1007/s12291-014-0446-0.

Quero, J., Marmol, I., Cerrada, E. and Rodriguez-Yoldi, 
M.J. (2020). Insights on potential application of polyphenol-rich dietary intervention on degenerative diseases management. Food and Function, 11(4), 2805-2825. https://doi.org/10.1039/d0fo00216j.

Ramaiya, S.D., Bujang, J.S. and Zakaria, M.H. (2018). Nutritive values of passion fruit (Passiflora species) seeds and its role in human health. Journal of Agriculture Food and Development, 4, 23-30. https:// doi.org/10.30635/2415-0142.2018.04.4

Rødtjer, A., Skibsted, L.H. and Andersen, M.L. (2006). Antioxidative and prooxidative effects of extracts made from cherry liqueur pomace. Food Chemistry, 99(1), 6-14. https://doi.org/10.1016/ j.foodchem.2005.07.011

Sasikumar, V., and Menon, S.G. (2011). Antioxidant activity and Nephroprotective effects of aqueous extract of Pleurotus Eous (Berk.) Sacc.: (APK1) pink Edible Oyster Mushroom. International Journal of Pharma and Bio Sciences, 2(3), 92-103.

Sepahpour, S., Selamat, J., Abdul Manap, M., Khatib, A. and Abdull Razis, A. (2018). Comparative analysis of chemical composition, antioxidant activity and quantitative characterization of some phenolic compounds in selected herbs and spices in different solvent extraction systems. Molecules, 23(2), 402. https://doi.org/10.3390/molecules23020402

Shukri, M., Mohd Zin, Z., Zainol, M.K., Said, S., Ngah, A. dan Abdullah, S.S. (2017). Integrating computerbased method into dietary intervention in children at Setiu wetland: A pilot study. Journal of Sustainability Science and Management, 12(2), 176182.

Shukri, N.A., Mohd Zin, Z., MohdMaidin, N., Hasmadi, M. and Zainol, M.K. (2020). Ramification of pH in pectinase-assisted extraction on the antioxidant capacity of Arabica spent coffee ground (SCG) extract. Food Research, 4(4), 1303 - 1311. https:// doi.org/10.26656/fr.2017.4(4).070

Tao, F., Liu, Y. and An, N. (2010). On the necessity of organic solvent extraction for carbon isotopic analysis of $\alpha$-cellulose: implications for environmental reconstructions. International Journal of Environmental Analytical Chemistry, 90(8), 605619. https://doi.org/10.1080/03067310903410949

Tapas, A.R., Sakarkar, D.M. and Kakde, R.B. (2008). Flavonoids as Nutraceuticals: A review. Tropical Journal of Pharmaceutical Research, 7(3), 10891099.

Tungmunnithum, D., Drouet, S., Kabra, A. and Hano, C. (2020). Enrichment in antioxidant flavonoids of stamen extracts from Nymphaea lotus L. using ultrasonic-assisted extraction and macroporous resin adsorption. Antioxidants, 9(7), 576. https:// doi.org/10.3390/antiox9070576

Yin, D.-D., Yuan, R.-Y., Wu, Q., Li, S.-S., Shao, S., Xu, Y.-J.,Hao, X.-H. and Wang, L.-S. (2015). Assessment of flavonoids and volatile compounds in tea infusions of water lily flowers and their antioxidant activities. Food Chemistry, 187, 20-28. doi:10.1016/j.foodchem.2015.04.032

Yu, C., Qiao, G., Qiu, W., Yu, D., Zhou, S., Shen, Y., Yu, G., Jiang, J., Han, X., Liu, M., Zhang, L., Chen, F., Chen, Y. and Zhuo, R. (2018). Molecular breeding of water lily: engineering cold stress tolerance into tropical water lily. Horticulture Research, 5(1), 73. https://doi.org/10.1038/s41438018-0086-2

Zainol, M.K., Abdul-Hamid, A., Abu Bakar, F. and Pak Dek, S. (2009). Effect of different drying methods on the degradation of selected flavonoids in Centella asiatica. International Food Research Journal, 16, 531-537.

Zainol, M.K., Wong, K.Y., Mohd Zin, Z., Kamarudin, K.S., Danish-Daniel, M. and Mamat, H. (2018). Effect of ethanol concentration in ultrasonic assisted extraction technique on antioxidative properties of passion fruit (Passiflora edulis) leaves. Malaysian Applied Biology, 47(6), 19-27.

Zhu, M., Zheng, X., Shu, Q., Li, H. and Zhong, P. (2012). Relationship between the composition of flavonoids and flower colors variation in tropical Water Lily (Nymphaea) cultivars. Plos ONE, 7(4), e34335. https://doi.org/10.1371/ journal.pone. 0034335 